\title{
Closing in on Story Openings and Closings: Evidence from Conversational Stories in Greek
}

\author{
Alexandra Georgakopoulou \\ King's College London \\ alexandra.georgakopoulou@kcl.ac.uk
}

\begin{abstract}
My aim in this paper is to show the benefits of incorporating a conversation-analytic perspective in the analysis of Greek storytelling data with regard to the endpoints of a telling, that is, the opening and the closing. I specifically explore the types of story openings and closings occurring in a data set that comprises the conversations of a group of female adolescents in a small town in Greece. I also discuss the salience of economic openings (Jefferson 1978) realized by certain conventionalized devices and the importance and local design of what I call counter stories in the stories' closing. I juxtapose counter stories to second stories (Sacks 1992), which have been found within CA to be frequent after a story's closing and I assess the frequency of second stories told by the same teller and not by a story recipient in my data. Overall, I argue that these systematic openings and closings in my data are interrelated with the types of stories told and the participants' roles and relations. Finally, I ponder the implications of this close connection for CA work on stories as talk-in-interaction.
\end{abstract}

\section{Keywords}

counter stories, economic openings, second stories, story openings-closings

\section{Introduction}

The study of Greek storytelling has often been seen as a treasure trove for culture-specificity within sociolinguistics and social anthropology. In fact, various studies have documented a culturally shaped dramatic and performed style of telling (e.g. Georgakopoulou 1997, Kostouli 1992, Tannen 1983, 1989). In turn, the status of narrative as an archetypal mode of communication, widely converged upon in the social sciences in general, has often resulted in linking this performed style of narration with the so called 'core' values of Greek society and culture, namely an avoidance of individualism, the prevalence of a solidary ethos, high involvement with intimates and a general need for relationality and connectedness (e.g. Archakis \& Tzanne 2009; for a discussion and critique, see Georgakopoulou 2004). This research has 
presented parallels with Labov's (1972) influential paradigm of narrative analysis and numerous studies in that vein, often referred to as 'post-Labovian' (as e.g. acknowledged in papers in Bamberg 1997). One of the main aims of this paradigm has been to establish cultural variation in terms of certain structural components that were postulated as universal. By now, the problems with the applicability of such a model have been amply demonstrated (e.g. papers in Bamberg 1997 op. cit.), in relation to storytelling in Greek too (e.g. Georgakopoulou 1997). More generally, there has been a notable shift towards contextualized approaches to storytelling that explore stories as being intimately linked with their local environments of occurrence and that avoid a straightforward mapping of linguistic forms to social or cultural functions. That said, as I have argued in recent work (2007), there is still much scope for examining storytelling in general, and in Greek in particular, as talk-in-interaction that is methodically produced and performs certain social actions in local contexts.

In this paper, my aim is to show the benefits of incorporating such a conversation-analytic perspective in the analysis of Greek storytelling data with regard to the endpoints of a telling, that is, the opening and the closing. To do so, I first outline the main assumptions of conversation analysis (henceforth CA) about narrative. Having discussed the importance of a story's endpoints within CA, I explore the types of story openings and closings salient in a data set that comprises the conversations of a group of female adolescents in a small town in Greece. I specifically discuss the frequency of economic openings (Jefferson 1978) and the importance and local design of what I call counter stories in the stories' closing. I also juxtapose counter-stories to second stories (Sacks 1992), which have been found within CA to be frequent after a story's closing. Overall, I argue that these systematic openings and closings in my data are interrelated with the types of stories told and the participants' roles and relations. Finally, I ponder the implications of this close connection for CA work on stories as talk-in-interaction.

\subsection{Stories as locally occasioned and sequentially implicative}

One of the main criticisms directed at work on narrative conducted within sociolinguistics (e.g. by Labov) as well as more generally within the social sciences, with the use of interviews, has been that it has viewed narrative as a detached, autonomous and self-contained unit with clearly identifiable parts. The crux of the counter-argument is that narrative occurs in some kind of a discourse environment, before and after other discourse activities and is thus enmeshed in its local surroundings. This view of narrative as a sequence, in itself part of a sequentially ordered event, is in Schegloff's terms, where the 
work on narrative "should be redirected" in order for us to get "toward a differently targeted and more compelling grasp of vernacular storytelling" (1997a: 101). What Schegloff has in mind is an approach to narrative based on CA that treats narrative as talk-in-interaction. CA has been instrumental in documenting conversations as sequentially ordered and methodical activities that allow us to uncover social order, roles and actions (e.g. see Sacks, Schegloff \& Jefferson 1974; also chapters in Antaki \& Widdicombe 1998).

The basic unit of structure for CA is to be found in the turn-taking system, particularly in the adjacency pairs, which tend to be sequentially organized (i.e. produced next to each other) two-part structures, in which given first parts make relevant particular second parts (e.g. questions-answers, greetingsreturn greetings). This suggests that narrative in CA has not been looked at in its own right and as the main object of inquiry, as, for instance, has been the case in narrative analysis. Instead, it has been seen as an activity that is enmeshed in local business and sequentially managed in the here-and-now of interactions (cf. Edwards 1997). As such, the telling of a story has been viewed as jointly drafted or co-authored by the participants involved raising different types of action and tasks for different interlocutors.

In the light of the above, a basic premise of CA work on narrative is that the telling of a story involves an entry into the surrounding discourse activity, a development and an exit. In this respect, endpoints matter enormously, and so does prior and upcoming talk that leads to a story and follows up from it respectively (e.g. see Jefferson 1978). Failing to pay attention to those and to include them in the analysis misses out on the irreducibly situational and locally occasioned aspects of storytelling as talk-in-interaction. By local occasioning, conversation analysts mean that "a good part of [the] meaning [of any talk] is to be found in the occasion of [the] production, in the local state of affairs that was operative at that exact moment of interactional time" (Antaki \& Widdicombe 1998: 4). On the other hand, the idea of sequential implicativeness accounts for the fact that once a story is told, it affects the way subsequent talk develops.

In the following discussion, I outline the main findings of CA with regard to introducing stories into conversations and exiting from them so as to examine their applicability and resonance in my data. I then discuss the main ways in which story openings and closings are being done in my data.

\section{Data and Methods}

The data for this study come from the self-recorded conversations of a group of four adolescent girls which I studied ethnographically in the period 
1998-2000. When the recordings started, the participants were 17 years old and living in a small town (25.000 inhabitants) in South Greece. At that point, they were re-sitting their University entrance exams and, as such, were outside the school framework. Their daily routine thus involved selfstudy in the mornings, private tuition in the early afternoons, and socializing thereafter, that mostly took the form of hanging out with one another and chatting at cafés. This regular socializing over a long period of time (the participants had known one another and, in their description, been "best friends" for 10 years) resulted in a dense interactional history, rich in shared assumptions that were consistently and more or less strategically drawn upon to suit various purposes in local interactional contexts. The data collection involved audio-taped data that two of the participants, Vivi and Tonia, recorded wearing audio-microphones; personal field-notes in the form of a diary and relatively unstructured interviews before, during and after the period of audio-recordings in which I asked participants about their thoughts on popularity, friendship, educational aims, relationships with parents, with boys, life in a provincial town, and engagement with popular culture. This paper is based on the stories that occurred in 20 hours of audio-recorded data.

\section{Analysis}

\subsection{Story openings}

One of the most influential conversation-analytic findings with regard to the sequential production of storytelling is to be found in Sacks' simple observation that "stories routinely take more than one utterance to do" (1992: 222). Put differently, stories suspend the normal rules for turn taking which allow for regular speaker change (see Sacks, Schegloff and Jefferson 1974). As a result, the launching of a story into a conversation involves securing floorholding rights for the teller. Sacks argues that this happens in the following three serially ordered steps:

1. Teller: Story Preface

2. Recipient: Request to hear the story

3. Teller: Story

In this three-part structure, the role of the preface is to be sought in the ways in which it aligns recipients, indicating to them what kind of activity is underway, more specifically, what kind of a story is going to be told. It thus raises specific tasks for the recipients, e.g. possible types of response appropriate to 
this type of story (Sacks 1992: 10). For instance, if the teller announces that the story is about terrible events, the audience will look for references to terrible events in the telling and will also be more likely to figure out appropriate ways to react to the storytelling. In addition to this systematic structure, story openings tend to be realized by recurrent linguistic devices. As Jefferson (1978: 224) showed, there are more or less conventionalized ways of launching a story that may range from what she called economic to elaborate story openings. She specifically discussed examples in which tellers opt for a storyprefixed phrase such as, "as a matter of fact..." or "that's true now...", or for a disjunct marker + phrase (such as "oh that reminds me of....") and then start their story in the same turn. But there are also other cases in which the teller introduces the story over a number of turns either to make sure that the recipients align as story listeners or because s/he has not been able to secure attention after the first attempt (cf. Ochs and Capps 2001: 135).

Drawing on the above insights, I analysed story openings in a sub-set of my data, namely in the 400 stories that occurred in 20 hours of recordings, with regard to the number and (co)-occurrence of opening markers. I also examined the actual steps or moves required to launch a story in my data and the extent to which the audience's request to hear a story was immediate. In terms of the latter, I found that 257 (out of 400) openings conformed to Sacks' three-part structure, while in 136 cases the recipient's response was missing ${ }^{1}$ and in that way the preface and the telling occupied the same turn. Below, I show what the main types of story prefaces were in such cases. Finally, only in 6 cases did the story launch take longer than the three steps: in 2 of those cases, one of the interlocutors needed more orientation about what was coming up, and in 4 cases, the interlocutors got caught up in something else (e.g. their coffees were served on one occasion as the story was about to begin) and abandoned the activity under way.

The above figures suggest an overwhelming preference for straightforward and 'quick' launches of stories in the data as opposed to stories emerging as a frequently contested activity, at least at their entry point, or as an activity that requires a great amount of interactional work and negotiation in order to be introduced into a conversation. In line with this, story openings in the data appear to be consistently economic and what is more, notably conventionalized. More specifically, there is a certain closed set of conventionalized devices

1 To be accurate, there was no audible/verbal response. As the data were not videotaped, I cannot exclude the possibility in some cases of the interlocutor(s) providing some kind of a non-verbal 'go ahead' signal (e.g. nodding, turning and looking toward the teller, etc.). Still, this does not alter the fact that the opening in these cases is economically done. 
that serve as 'generic framing devices' (Bauman 2004:4) in that they 'carry with them sets of expectations concerning the further unfolding of the discourse' (ibid.): in this case, not only do they render the activity to follow recognizable as a story, but they also signal what type of story is going to follow. Elsewhere (Georgakopoulou 2007), I have discussed how the stories told in the group in question depart from the personal experience past events non-shared story that has monopolized the interest of narrative analysis. Three main types of stories in the data are what I have called breaking news, projections and shared stories. Breaking news involves very recent (i.e. yesterday's) events, consisting of either sightings of men that the participants are interested in, or less frequently, of reports of mediated interactions (e.g. mobile phone calls) with peers. ${ }^{2}$

Projections involve (near) future encounters with the men-talked-about and are episodically organized interactions of the 'I'll say- s/he'll say' type. Contrary to the predominance of past events stories in conventional narrative analysis, projections were by far the most common type of storytelling in this group. The planning of the taleworld involves a turn-by-turn co-authoring and negotiation of details in the taleworld, particularly regarding the story's orientation (Labov 1972), namely the parts that relate the when and where of the taleworld. Finally, shared stories involve more or less elliptical tellings of known events or known (as in previously told) stories.

Each of these recurrent types of stories is launched with equally recurrent opening devices. Specifically, breaking news is routinely launched with a 'guess who' type of question that includes a time and/or place marker and that forms some kind of a pre-telling (Schegloff 1997b: 516). As we can see in the example below, a very common audience response is to echo this (pre-telling) question, but as being addressed to the teller (line 2 below). This serves as a request to hear a story, a go-ahead signal:

(1) Participants: $\mathrm{T}$ (onia), $\mathrm{F}$ (otini)

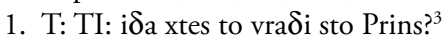

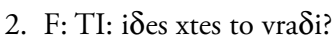

3. T: Pi $\gamma$ ame me to baba mu kata tis enja $[\ldots]$

\footnotetext{
${ }^{2}$ My data were collected before the explosion of text-messaging or of social networking sites.

${ }^{3}$ The transcription conventions used in the cited excerpts are as follows: Overlapping utterances are marked by $/ /$; = connects latched utterances; intervals in and between utterances are given in small untimed pauses: (.) indicates a pause that it less than 0.5 seconds. A colon marks an extension of the sound it follows; a double colon marks a longer extension. Punctuation marks are used to indicate intonation: a question mark indicates rising intonation. $(())$ indicate editorial comments. CAPITALS indicate speech that is louder than the surrounding talk. Underlining indicates emphasis.
} 
1. T: WHA:T did I see last night at Prince ((a bar))?

2. F: WHA:T did you see last night?

3. T: I went with my dad at about nine o'clock $[\ldots]$

It is notable that only one-third of the breaking news stories are launched into the conversations as first or new topics. The rest of the breaking news stories are chained stories, that is, they follow previously told breaking news stories. This observation is relevant for the stories' closing too.

Projections are also typically launched with a question that is however very different to the one of breaking news. This type of question in future tense serves as an invitation to the interlocutors for a co-construction of the story to follow, as we can see in the use of the first person plural (line 1) below:

(2) Participants: $\mathrm{F}$ (otini), V(ivi)

1. F: Pedja (.) ti $\theta$ a kanume avrio? Iremiste ce sjopite. TI $\theta$ a kanume?

2. V: Katarçin $\theta$ a pas na kanis ena krio banjo=

1. F(otini): Guys (.) what are we going to do tomorrow?

2. Contain yourselves and be silenced. WHAT are we going to do?

3. V(ivi): First of all you'll have a cold bath [...]

In line 2 above, Vivi orients to Fotini's bid for co-construction by offering the beginning of what turns out to be the first of many sequenced story events. In terms of their relationship with prior talk, projections tend to be more independent from other stories than both breaking news and shared stories. To be specific, $65 \%$ of the projections in the data are not preceded by another story; they are either triggered by a topic in the conversation or they are introduced as new topic, after a prior topic has closed. Thus, in terms of their inter-relationships with other stories, they tend to serve as the stories into the telling of which another story (normally a shared story) is embedded.

Finally, shared stories which are overwhelmingly launched in the course of the telling of a projection, are typically introduced as follows:

Teller: Discourse Marker: "Let me tell you something" ("Shall I tell you something"? Na su po kati) +/OR question containing story abstract or other material for the recipient(s) to recognize the story +/OR reference to previous telling(s)

(Knowing) ${ }^{4}$ Recipient: Answer (confirmation) +/OR Clarification question +/OR Double-checking.

As I have shown elsewhere (Georgakopoulou 2001), the marker "na su po kati" ("shall I tell you something") signals that the upcoming talk is going to

4 That is, one who knows of the story's events. 
re-frame prior talk or introduce some kind of a shift in the activity under-way, in this case the opening of a story. In the example below, taken from a conversation between two participants, Vivi and Tonia, we can see that this marker (line 1) is followed by an abstract ("I went through the same thing") that connects the upcoming telling with the prior talk and by a reference to a prior telling ("I've told you the story", 1. 2). In line 3, Tonia provides assurance or recognition of the story referred to by supplying information about one of the characters in the story.

(3) Participants: V(ivi), T(onia)

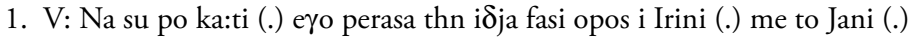

2. su xo pi tin istoria $=$

3. $\mathrm{T}:=$ Me ton tipo pu ta çe me tin gzaderfi su=

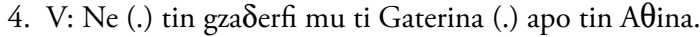

1. V: Let me tell you something (.) I went through the same thing as Irene (.) with Jannis (.)

2. I've told you the story=

3. $\mathrm{T}:=$ The guy who was involved with your cousin=

4. V: =Ri:ght (.) my cousin Caterina (.) from Athens.

Establishing mutual reference is key to the opening of shared stories and the process routinely takes the form of Sacks' three-part structure, as we can see above. In this case, however, the audience response is aimed at confirming shared knowledge with the teller regarding the upcoming story. This confirmation seems to take the place of the request to hear the story but is perhaps treated as such, given the fact that tellers routinely proceed to tell the story. Although as in Sacks' data, in this case too, story prefaces are aimed at letting the other participants know that a storytelling is being proposed, the difference in my data is that prefaces of shared stories set out to enable participants to recognize the upcoming story and the task then for the participants is to display that recognition before the telling starts.

Overall, the economy and conventionalization of the above story openings suggest that an entry into a story in my data is not primarily a turn that is aimed at granting the teller (strong) telling rights. Instead, other functions and social actions come to the fore, as for instance the need to establish mutual reference with the addressees before the story's telling (in the case of shared stories) or the need to raise for them the task of the upcoming story's co-construction (in projections). We have also seen how the opening displays the type of story that is forthcoming. This is something that, in the CA study of openings, has not been highlighted in favour of an emphasis on the role of openings for securing the teller the floor. If we probe more into this relationship between story openings and story type, we can argue that at the heart of 
the conventionalization of the story openings is the frequent circulation of specific kinds of stories in this group of intimates, which has resulted in the development of specific local norms around storytelling: e.g. what stories are told, how, and as we see in the discussion below, how they relate to one another. ${ }^{5}$ Closely related to this is the participants' closeness and friendship which seems to have resulted in a loosening of the requirement for tellers to ask for permission to tell a story in elaborate ways. Similar considerations apply to story exit mechanisms.

\subsection{Story closings and exits}

Jefferson (1978) described story closings in equal detail as the openings, noting the importance of paying attention to the need for re-engagement of turnby-turn talk that had been suspended during the telling, after story completion. She specifically showed how the tellers signal that their story has reached an end and how in turn the audience use a variety of techniques to display their understanding of the preceding story and to signal how their contributions follow up from that: e.g. by contributing topically relevant talk, evaluative comments on the characters or the moral of the story (cf. Schiffrin 1984). ${ }^{6}$ According to CA research, one of the most routine responses to a story is to provide a second story, that is, a thematically or otherwise related account that echoes and amplifies the point made by the previous story. In this way, second stories form a procedure through which the audience as current tellers display their understanding of the story told, and in the process constitute a thematic continuity backwards (Coates 2001: 93).

In light of the above findings, the first thing to note in relation to the data at hand is the difficulty of establishing a story's closing. Both in CA research and in structural analyses (by Labov, for instance), there is an assumption that stories are activities with a clear beginning, middle, and end. This linear development of stories does not sit well with the situation in the data, mainly due to the fact that stories tend to be intertextually linked with one another

5 This is confirmed by the ethnographic study of the group, the discussion of which is beyond the scope of this chapter (for an analysis, see Georgakopoulou 2007, chapters 1 and 2).

${ }^{6}$ Jefferson (1978) also showed how audience reactions that occur prematurely (i.e. before a story ends) put the onus on the teller to continue with the telling and ensure that their story has been understood in the ways in which they have proposed. Similarly, if tellers reach a story's closing but the audience do not respond in appropriate ways, that is, if they remain silent or if they offer tangential talk that does not show the story's implicativeness for what is to follow, tellers tend not to challenge these responses but instead to propose that the story has not ended yet and to offer a further story component until they get relevant responses (idem: 232-234). 
and interwoven in their tellings. I have discussed these intertextual links in detail elsewhere (2007, ch 2). In brief here, I mention that breaking news tends to lead to the tellings of projections: the main character remains the same, namely the man who was seen, but is placed in various future scenarios of e.g. romantically meeting up with one of the girls. Similarly, shared stories are hardly ever told independently of another, ongoing story. As their main role is argumentative, that is, to put forth a view that under-cuts or openly opposes the ongoing story's events and/or evaluation, they tend to occur in the course of a story's telling, particularly that of a projection. In this way, the experience accumulated from past events is brought in to inform future events. Once a shared story is embedded into a current projection, it essentially alters its progression and an intricate going back and forth between the two tellings is very common in the data, that is, from the shared story moving back to the projection to draft a revised version, and then moving out of that too and back into the shared story. This dynamic intermingling necessitated in my analysis an equally dynamic definition of story closings as more or less momentary exits rather than clearly demarcated endings. It is within this framework, then, that we can talk about follow-up or response-talk to stories in the data.

As it may have become apparent by now, the most notable finding in the data at hand in terms of follow-up talk and responses to stories lies in the frequency of further stories. To put this otherwise, stories seem to work in the data as activities that cluster together and story talk routinely generates further story talk. To be specific, in 384 out of the 400 stories analysed, the exit from a story is immediately followed up and in many cases precipitated by another story. A significant number (263) of these stories serve as counter stories. ${ }^{7}$ I am coining this term so as to highlight the difference of such stories from second stories, which CA has documented as frequent responses to stories. While second stories seek to establish common experience with the foregoing story and by extension, alignment with the teller (Sidnell 2003), counter stories tend to dis-align with the foregoing story, mainly by offering a competing interpretation to its events. The term 'counter stories' refers to these stories' functional/social action orientation, that is, very simply, to what they do in their local environments. In terms of story type or genre, counter stories mostly (in 228 out of 263 cases) ${ }^{8}$ take the form of shared stories, which we

\footnotetext{
7 The term is not to be confused with that of 'counter narratives', which is set in contrast to 'master-narratives' (for a discussion, see contributions in Bamberg \& Andrews 2004).

8 The rest of the cases of counter stories are projections.
} 
discussed above. In other words, counter stories draw on shared (between teller and interlocutors), known or previously told events in order to put forth a point of view that competes with or undermines that of the ongoing story.

Another interactional feature of the telling of counter stories is that they tend to open up a space for contestation and negotiation between the interlocutors, which in itself engenders further narrative talk. This is so on the basis that a counter story is very commonly rebutted by another counter story yielding to yet another counter story, so that the chaining of counter stories ends up being very common in the data. Let us have a look below at how such a chained counter story is being introduced. In this case, Tonia has been trying to contest the projection that the others, mainly Vivi, are jointly constructing for her, which involves asking a man out. Tonia produces five counter stories in this storytelling event, all of which relate, more or less elliptically, shared events. These events are put forth as evidence that the man in question is not interested in her and so she should not put herself in a potentially embarrassing position, by asking him out:

(4) Participants: $\mathrm{T}$ (onia), Vivi.

1. T: Na su po c'ali fasi

2. $\Delta$ en gatalave tote pu me petiçe brosta sto Blok?

3. tt:! Ekana eyo ecini tin ora?

1. T: Let me tell you of another incident

2. didn't he realize when he bumped into me outside Block?

3. wha:t! was I doing there at that sort of time?

The reference in this counter story's preface to 'another incident' (line 1) is indicative of the story's positioning in a series of response moves to a previous story. The preface to the counter story in example 5 below, also a story of shared events, is the second story to be told by Tonia in this storytelling event. Again, the aim is to cancel out the point of the ongoing story of projected events, which places Tonia in a scenario of asking a man out. In the entirety of this storytelling event, the point of all five counter stories, told in the course of the story of projected events, as embedded narrative activities, seems to be that the man in question has had many chances of asking her out in the past.

(5) Participants: $\mathrm{T}$ (onia), Vivi.

1. T: Epoçi yimnastiriu (.) Oima:se?

2. pu 'xame katevi tis skales

3. ce me to pu ton vlepume na kateveni ksa::naririzume pano

4. ce citarame san ili $\theta j \alpha$

5. ce meta katsame mexri tis pedemisi 
6. ce kaname ciljakus (.) ce kakarizame.

7. $\Delta \mathrm{e}::$ n gatalave tote?

1. T: The gym era (..) reme:mber?

2. The time we'd gone downstairs

3. and the minute we see him we go a::ll the way up again

4. and start looking at him like two idiots

5. and then we stayed until half past five

6. doing tummy exercises (.) and giggling

7. Didn't he realize then?

Counter stories are thus used as argumentative devices and as embedded responses to an ongoing telling of a story (of projected events) that set out to undercut the point of the telling, either by disputing the events or, more commonly, their interpretation by the teller.

Even though they are less frequent than counter stories, second stories also occur in the data (121 second stories compared to 263 counter stories out of 400 ), but what is notable in this respect is the frequency with which second stories are actually told by the same teller as that of the foregoing story. 92 out of the 121 second stories in question are told by the same teller. This often happens in the case of breaking news when the same teller goes on to tell of another sighting either of another male character or of the same character as in the foregoing story. For instance, Tonia follows up her story about 'who she saw at Prince' (excerpt 1 above) with another breaking news, a sighting of a man nicknamed by the group as Danny. She opens her story as follows:

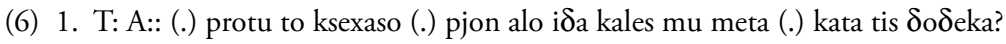

1. T: O::h (.) before I forget (.) who else did I see my dears afterwards (.) at around midnight?

If seen in the context of what Sacks has proposed about second stories, the teller telling a second story as a response to her own story may seem counterintuitive. And, certainly, the social action of the audience providing an appropriate response to the foregoing story showing understanding of its point does not make much sense in the case of a second story told by the same teller. However, if seen in the context of tellings in the data, it becomes an utterly meaningful choice. Stories in the data are so interwoven with one another as well as being jointly constructed by the interlocutors that the dyad of tellerrecipients is simply too reductionist to capture the complexity of participation roles involved (cf. Ochs \& Capps 2001). Similarly, second stories told by the same (main) teller of the foregoing story have to be seen in the context of the closings being a dynamic and fluid process of exiting, as we described it above. Indeed, a fuller account of the phenomenon needs to take into account 
differentiated participation roles and telling rights. Second stories by the same teller are mostly told by the main storyteller of the group, namely Vivi, who, as I have shown elsewhere (2006), emerged from the group's ethnography as the leading figure. Vivi's discourse activities, including that of telling stories, clearly show that she was granted more floor-holding rights than the other interlocutors and that her contributions tended to be ratified and aligned with. ${ }^{9}$ Vivi is not only an assured performer in the group but also an effective assessor of events and characters talked about. As a result, her second stories, in addition to being shaped by, as well as consolidating, her strong performance and floor holding rights, also allow her to provide further support and experiential evidence for the views that she puts forth through their telling.

On the basis of the above finding, we can claim that not only is there systematicity in second stories serving as a response to a foregoing story but that there is also systematicity to be found in which participant gets to tell a second story. Furthermore, depending on established participation roles and telling hierarchies, the same teller can be in a position of following up on his/her story with a second story.

\section{Conclusions}

This paper began with the view that the study of narrative as talk-ininteraction, as advocated by CA, can significantly enrich our understanding of the phenomenon. I argued that by paying attention to the local occasioning and the sequential implicativeness of stories, CA has managed to shed light on the systematic ways in which stories are introduced and responded to in interaction. I subsequently examined the validity of influential findings within CA regarding story openings and closings in a data-set of stories from the conversations of a group of female adolescents. There is a longstanding tradition of approaching narrative data in languages other than English with a more or less explicitly stated need to uncover culture-specificity in those data, almost as an exercise of justifying or legitimating the analyst's preoccupation with them. At the beginning of this paper, I claimed that this type of work has not been without its methodological or analytical pitfalls, and that it has often led to over-generalizations. This is by no means to say that there is no validity in it

${ }^{9}$ As I have argued (2006), this role that Vivi played in the team, was intimately linked with her gendered and specifically heterosexual identities, which the interlocutors looked up to and connected with popularity in the heterosexual market. 
or to deny its place and continuing relevance for sociolinguistics in Greek. Instead, the point of the preceding discussion has mostly been exploratory: part of the aim has been to see how far we can go in a particular data-set with the epistemological perspective of CA that does not assume a priori the relevance of 'Greekness' in the data in question nor does it dictate to the analyst to try to locate it in the actual language and interactional choices. It is safe to say that the sequential analysis of the data has upheld the CA argument that there is systematicity in the ways in which story openings and closings are done. However, as we saw above, it also showed the need for extending the scope of CA work on story endpoints.

Specifically, with regard to the story openings, I reported an overwhelming preference in the data for straightforward and quick launches of stories as well as for economic story openings realized by certain conventionalized devices. These systematic ways of opening a story, I argued, are intimately linked with the types of stories told and in turn the intimate relations between participants which have resulted in the establishment of local storytelling norms.

My analysis of the story closings led to findings that seem to counter the main assumptions of CA work on them. These include the difficulty of establishing neat closing and exit points, mainly because tellings of stories are interwoven in the data; the salience of counter stories which by their function of dis-aligning, question the $\mathrm{CA}$ reported preference for alignment with the foregoing story upon its completion; and finally, the frequent occurrence of second stories by the same teller which makes apparent the need to consider differentiated telling roles more fully in relation to a story's endpoints.

The above findings point to avenues that future interactional work on story openings and closings can take in order to advance our understanding of narrative as talk-in-interaction. In particular, the systematic trends that CA has documented in the introduction of stories can be further explored and finetuned in relation to the type and structuring of telling that follows them. Within a framework that accepts that story openings are consequential for what is going to come, we can expect to find such a systematic relationship, as we have found in this paper. Influential studies for instance by C. Goodwin (e.g. 1984, 1986) and M.H. Goodwin (e.g. 1997) have so far shown how audience diversity in terms of e.g. which interlocutor knows of the story's events and who does not know, is instrumental in shaping the way a story is launched and how it subsequently unfolds. The findings of this paper add insights into how differentiated participation roles but also the actual type of the story told inter-relate with how a story may be introduced into a conversation and taken up by interlocutors. In a similar vein, there is much scope for exploring the systematic relations that different story openings may present 
with subsequent tellings from a sequential or structural point of view, that is, what story components we can expect to find, how much they be elaborated, and so on. Some of my earlier work (2005) has already pointed to such links, for example, by showing that story prefaces aimed at establishing mutual reference with the interlocutor (as in the case of shared stories, which we discussed above) normally do not project a long telling. Instead, they are typically followed by a mini-telling of the story, which comprises its narrative skeleton, that is, a quick reference to or reminder of its events and of their resolution.

Furthermore, this paper's findings about both story openings and endings suggest that the study of storytelling within CA has been somewhat restrictively connected with the turn-taking system and the requirement that stories set for strong floor-holding rights, as well as with a teleological view of storytelling activities as presenting clear beginnings, progression and end. In my view, this 'bias' has had to do with the type of stories that particularly earlier CA work on narratives has analysed. We have, for instance, seen in this paper that once we move away from stories of non-shared, past events to stories of shared, future or very recent (ongoing) events, the story prefaces and closings do very different work, one that is tailored to the specific social actions that such stories perform in their local contexts. Furthermore, though, my claim is that such local actions cannot be disassociated from what I would call larger contextual factors that may pertain beyond and above the local interactional context, such as the participants' identity aspects, their history of relationship and interaction leading up to the here-and-now of an interaction, the sociocultural framework within which they operate, etc. CA has all too often been critiqued for its too nose-to-data approach that does not easily abstract from local contexts and does not allow linkages between those and larger contexts and processes above and beyond single communicative events (e.g. Wetherell 1998 , for an early yet classic example of such a critique). This is a major ongoing discussion in the literature that cannot be done justice to here. Certainly, my own epistemological position, as I have documented it in other work (e.g. De Fina \& Georgakopoulou 2008), is in favour of a practice-based approach to storytelling that goes beyond CA and its focus on single communicative events and includes in its remit, amongst others, ethnographic perspectives and attention to how discourse activities both travel across contexts (i.e. are re-contextualized) and are inter-related (i.e. intertextually linked). For the purposes of this paper, however, I followed a line specifically focused to the endpoints of storytellings in my data with a twofold aim: on the one hand, I have tried to illustrate the benefits of using CA in the analysis of such endpoints, particularly with regard to a story's embeddedness in its local interactional surroundings (co-text), the significance of which should not be 
overlooked in the analysis. On the other hand, I have also shown the merits of a mutually informing process of drawing on CA but also going back to it with fresh insights from the specific data (and the site) analysed that are far removed, both linguistically and contextually, from the original and in some ways canonical data that CA has employed, in particular in relation to storytelling. Such an engagement with CA, a framework that is committed to documenting local context contingencies rather than the influence of broader, sociocultural contexts on data can actually come with renewed possibilities for language-focused analyses in relation to Greek data that until recently tended to commit to a pre-conceived and thus potentially limiting agenda of documenting Greekness. These possibilities include employing Greek data to build resonances, critique, depart from, add contextualized nuance etc. to existing findings in CA, which can lead to creative and on a par synergies between language-specific and CA analyses.

\section{References}

Antaki, Charles and Sue Widdicombe (eds.).1998. Identities in talk. London: Sage.

Archakis, Argyris and Ageliki Tzanne. 2009. Constructing social identities through story-telling: Tracing Greekness in Greek narratives. In Georgakopoulou, Alexandra \& Lytra, Vally (eds.), Language, discourse and identities in Greek contexts. Special Issue. Pragmatics 19. Online: www.ipra.be (Last accessed: 20/01/2010).

Bamberg, Michael (ed.). 1997. Oral versions of personal experience. Three decades of narrative analysis. Special Issue. Journal of Narrative and Life History 7 (1-4).

Bamberg, Michael and Molly Andrews (eds.). 2004. Considering counter narratives: Narrating, resisting, making sense. Amsterdam: John Benjamins.

Bauman, Richard. 2004. A world of others' words. Cross-cultural perspectives on intertextuality. Oxford: Blackwell.

Coates, Jennifer. 2001. My mind is with you: story sequences in the talk of male friends. Narrative Inquiry 11: 1-21.

De Fina, Anna and Alexandra Georgakopoulou. 2008. Analysing narratives as practices. Special Issue. Journal of Qualitative Research 8: 379-387.

Edwards, Derek. 1997. Structure and function in the analysis of everyday narratives. In Michael Bamberg (ed.), Oral versions of personal experience: Three decades of narrative analysis. Journal of Narrative \& Life History 7: 139-146.

Georgakopoulou, Alexandra. 1997. Narrative performances: A study of Modern Greek storytelling Amsterdam/Philadelphia: Benjamins.

Georgakopoulou, Alexandra. 2001. Arguing about the future: on indirect disagreements in conversations. Journal of Pragmatics 33: 1881-1900.

Georgakopoulou, Alexandra. 2004. Reflections on language-centered perspectives on Modern Greek society and culture. Kampos. Cambridge Papers in Modern Greek 12: 45-68.

Georgakopoulou, Alexandra. 2005. Same old story? On the interactional dynamics of shared narratives. In Uta Quasthoff \& Tabea Becker (eds.), Narrative interaction. Amsterdam: John Benjamins. 75-91. 
Georgakopoulou, Alexandra. 2006. Small and large identities in narrative (inter)-action. In Anna De Fina, Deborah Schiffrin \& Michael Bamberg (eds.), Discourse and identity. Cambridge: CUP. 83-102.

Georgakopoulou, Alexandra. 2007. Small Stories, interaction and identities. Amsterdam/ Philadelphia: John Benjamins.

Goodwin, Charles. 1984. Notes on story structure and the organization of participation. In J.M. Atkinson \& John Heritage (eds.), Structures of social action. Cambridge: CUP. 225-246.

Goodwin, Charles. 1986. Audience diversity, participation and interpretation. Text 6: 283-316.

Goodwin, M.H. 1997. By-play: Negotiating evaluation in story-telling. In Gregory R. Guy, Crawford Feagin, Deborah Schiffrin \& John Baugh (eds.), Towards a social science of language: Papers in honor of William Labov, vol. 2: Social interaction and discourse structures. Amsterdam/Philadelphia: John Benjamins. 77-102.

Jefferson, Gail. 1978. Sequential aspects of storytelling in conversation. In Jim Schenkein (ed.), Studies in the organisation of conversational interaction. New York: Academic Press. 219-249.

Kostouli, Triantafillia. 1992. On the structure of textual rhetoric: some evidence from Greek narratives. Text 12: 373-395.

Labov, William. 1972. Language in the Inner City. Philadelphia: University of Pennsylvania Press.

Ochs, Elinor and Lisa Capps. 2001. Living narrative. Cambridge, MA: Harvard University Press.

Sacks, Harvey. 1992. Lectures on conversation. Vols I \& II, ed. By Gail Jefferson. Oxford: Blackwell.

Sacks, Harvey, E.A. Schegloff and Gail Jefferson. 1974. A simplest systematics for the organization of turn taking for conversation. Language 50: 696-735.

Schegloff, E.A. 1997a. 'Narrative analysis' thirty years later. Journal of Narrative and Life History 7(1-4): 97-106.

Schegloff, E.A. 1997b. Practices and actions: Boundary cases of other-initiated repair. Discourse Processes 23: 499-545.

Schiffrin, Deborah. 1984. How a story says what it means and does. Text 4: 313-346.

Sidnell, Jack. 2003. Constructing and managing male exclusivity in talk-in-interaction. In Janet Holmes \& Miriam Meyerhoff (eds.) Handbook of language and gender. Oxford: Blackwell. 327-352.

Tannen, Deborah. 1983. 'I take out the rock-dok!' How Greek women tell about being molested (and create involvement). Anthropological Linguistics 25: 259-374.

Tannen, Deborah. 1989. Talking voices. Repetition, dialogue and imagery in conversational discourse. Cambridge: Cambridge University Press.

Wetherell, Margaret. 1998. Positioning and interpretative repertoires: conversation analysis and post-structuralism in dialogue. Discourse \& Society 9: 387-412. 


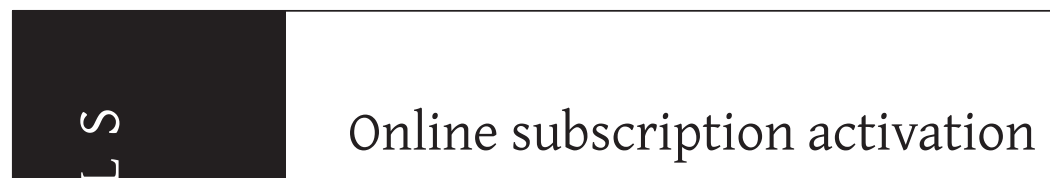

Institutional subscribers to the electronic-only or electronic+print version of this title have access to all online back files. If your institution does not already hold an IngentaConnect registration, you can register and activate by going to: www.ingentaconnect.com/register/institutional

The whole process involves 5 simple steps and should take no more than 5 minutes.

\section{Step I - Institutional and administrator contact details}

You will need to enter your organization name, address, and provide an administrator contact name and email address.

\section{Step 2 - Authentication}

Authentication details: How do you want to access the publications you are subscribed to? IP address/range or User name and password.

\section{Step 3 - Administrator sign in}

This will be the login to access the administrator home page. From here you can create payment accounts, setup subscription access, view statistics, sign up for alerting, change administrator or authentication details, and configure library branding. The administrator username must be different from the shared username created in the previous step.

\section{Step 4 - Confirmation of Registration}

The confirmation screen will provide you with your IngentaConnect customer ID number. This is your registration ID.

\section{Step 5 - Set up subscriptions}

You can now click on the link "set up subscriptions" to add your institutional subscriptions. Search for or browse to the journal title(s) you subscribe to.

Enter your publisher customer (CU-)number in the box provided to the right of the publication title and tick the box to the left of the publication title. without entering this number.)

Click the „add" link at the top or bottom of the journal list.

Alternatively, you may ask your subscription agent to set up access for you.

If there are any problems accessing the journal, please contact the helpdesk at Ingenta directly via the following e-mail address: help@ingentaconnect.com.

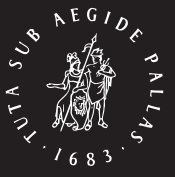

B R I L L 